\title{
Evidence for the existence of adaptive thermogenesis during weight loss
}

\author{
Eric Doucet ${ }^{1,2}$, Sylvie St-Pierre ${ }^{1}$, Natalie Alméras ${ }^{2}$, Jean-Pierre Després ${ }^{2}$, Claude Bouchard ${ }^{3}$ and Angelo \\ Tremblay ${ }^{1 *}$ \\ ${ }^{1}$ Division of Kinesiology, Laval University, Ste-Foy, Québec G1K 7P4, Canada \\ ${ }^{2}$ Department of Food Science and Nutrition, Laval University, Ste-Foy, Québec, G1K 7P4, Canada \\ ${ }^{3}$ Pennington Biomedical Research Center, Louisiana State University, Baton Rouge, Louisiana 70808, USA
}

(Received 16 June 2000 - Revised 2 September 2000 - Accepted 13 December 2000)

\begin{abstract}
The present study was performed to further investigate the adaptive component of thermogenesis that appears during prolonged energy restriction. Fifteen obese men and twenty obese women underwent a 15-week weight-loss programme. During this programme, body weight and composition as well as resting energy expenditure (REE) were measured at baseline, after 2 and 8 weeks of energy restriction $(-2929 \mathrm{~kJ} / \mathrm{d}$ ) and drug therapy (or placebo), and finally $2-4$ weeks after the end of the 15-week drug therapy and energy restriction intervention, when subjects were weight stable. Regression equations were established in a control population of the same age. These equations were then used to predict REE in obese men and women at baseline, after 2 and 8 weeks, as well as after the completion of the programme. In both men and women body weight and fat mass were significantly reduced $(P<0.05$ in all cases) while fat-free mass remained unchanged throughout the programme. At baseline, REE predicted from the regression equation was not significantly different from the measured REE in men, while in women the measured REE was $13 \%$ greater than predicted. After 2 weeks of energy restriction, measured REE had fallen by 469 and $635 \mathrm{~kJ} / \mathrm{d}$ more than predicted and this difference reached 963 and $614 \mathrm{~kJ} / \mathrm{d}$ by week 8 of treatment in men and women respectively. Once body-weight stability was recovered at the end of the programme, changes in REE remained below predicted changes in men $(-622 \mathrm{~kJ} / \mathrm{d})$. However, in women changes in predicted and measured REE were no longer different at this time, even if the women were maintaining a reduced body weight. In summary, the present results confirm the existence of adaptive thermogenesis and give objective measurements of this component during weight loss in obese men and women, while they also emphasize that in women this component seems to be essentially explained by the energy restriction.
\end{abstract}

Weight loss: Resting energy expenditure: Adaptive thermogenesis

Resting energy expenditure (REE) accounts for the largest proportion of daily energy expenditure (Ravussin et al. 1986). Since small changes in any component of daily energy expenditure can lead to a substantial impact on daily energy balance, a relative change in its largest component, i.e. REE, has a larger impact on energy balance than the same relative change in the thermic effect of food, for example. Indeed, it has been suggested that individuals characterized by a reduced REE are more prone to weight gain over time (Ravussin et al. 1988). This is an important issue in the context of weight reduction, because of the potential role of REE in the maintenance of weight stability in a reduced-obesity state (Pasman et al. 1999). The fact that fat-free mass (FFM) is the major determinant of REE is also well established (Ravussin et al. 1986), even though fat mass (FM; Ferraro et al. 1992), more particularly fat from the abdominal region (Dionne et al. 1999), is also a significant correlate of $24 \mathrm{~h}$ energy expenditure. It is expected that weight loss, which produces a decrease in both FM and FFM, would produce a decrease in REE (Leibel et al. 1995; Doucet et al. 2000) that would persist even when a reduced obese state has been achieved (Leibel \& Hirsch, 1984). It should also be expected that the decrease in REE that occurs during weight loss would be proportional to the decrease in body substance. However, it would seem that, in the case of underfeeding studies, acute energy restrictions can also lead to reductions in REE which are not entirely explained by changes in body composition (Prentice et al. 1991; Wadden et al. 1996). In addition, it has been shown that the decrease in body weight induced by exercise training is related to the decrease in sleeping metabolic rate, despite the fact that an

\footnotetext{
Abbreviations: FFM, fat-free mass; FM, fat mass; REE, resting energy expenditure.

* Corresponding author: Dr Angelo Tremblay, fax +1 418656 2441, email angelo.tremblay@kin.msp.ulaval.ca
} 
increase in FFM was also observed (Westerterp et al. 1994). A sustained depression of sleeping metabolic rate has also been reported in response to weight loss induced by vertical banded gastroplasty (van Gemert et al. 1998). These observations fit well with results demonstrating that, in response to a $10 \%$ weight loss, REE fell by $573 \mathrm{~kJ} / \mathrm{d}$ more than had been predicted from the relationship established at baseline in the same subjects (Leibel et al. 1995). Taken together, these observations imply that, in human subjects subjected to energy-restricted diets and ultimately to weight loss, the reduction in REE might not always be proportional to the decrease in body substance. In such cases a greater energetic efficiency, i.e. an adaptive component of thermogenesis, often appears. In such a context, it would be clinically relevant to be able to give objective measurements of these deviations from the predicted decrease in REE and to identify those individuals who are prone to deviate significantly from the predicted REE during weight loss, in order to develop adequate treatment strategies for these individuals.

The present study was thus conducted: (1) to confirm the existence of a greater than predicted decrease in REE; (2) to give objective measurements of these deviations; (3) to identify predictors of these deviations in obese men and women subjected to a prolonged energy restriction aimed at inducing weight loss. This objective was achieved by comparing measured values of REE to values obtained from a regression equation established in a large number of subjects of comparable age measured in the same laboratory.

\section{Methods}

Fifteen men and twenty premenopausal women, aged 44.3 (SE 1.7) and 41.4 (SE 1.1) years respectively, participated in the present study. Subjects were given either fenfluramine $(60 \mathrm{mg}$ ) (twelve men and fifteen women) or a placebo (three men and five women) once daily for the 15-week duration of the programme. Since this protocol was a double-blind study, subjects were randomly assigned to a group in a ratio $5: 1$ for the drug or placebo treatment respectively. This pharmacological approach was accompanied by a non-macronutrient-specific energy restriction of approximately $2929 \mathrm{~kJ} / \mathrm{d}$. In order to achieve this energy restriction, the food exchange system from the Association Diabète Québec (1994) was explained to each subject by a nutritionist. In this system, foods are categorized into the seven following groups: milk and dairy products; meat and substitutes; vegetables (one portion containing about $7 \mathrm{~g}$ carbohydrates), other vegetables (one portion containing about 3-4 g carbohydrates); fruits; bread and cereals; fat (including oils, margarine, shortening, butter; nuts and seeds, etc.). Subjects were allowed to eat a certain amount of each of these food groups in a proportion that matched the macronutrient composition of their diet before the beginning of the programme, and which also corresponded to the prescribed energy restriction.

During this programme, subjects had to come to the laboratory every 2 weeks for a control session, during which they were weighed and asked about compliance. If subjects had lost $<1 \mathrm{~kg}$ during the previous 2 weeks and if it was ascertained that the energy-restricted diet had been respected during this period, the energy restriction was adjusted to ensure a progressive weight loss for the remainder of the programme. The visits also served to verify drug compliance and to renew a subject's prescription, when relevant. Measurements of dependent variables in the obese subjects were performed at baseline and after 2 and 8 weeks, as well as 2-4 weeks after the end of the 15week weight-loss programme, hence 17-19 weeks after the beginning of the programme. Control groups of men ( $n$ 112 ) and women $(n$ 166), aged $45 \cdot 2$ (SE 0.7) and 43.9 (SE $0 \cdot 6)$ years respectively, were selected from the phase 2 database of the Québec Family Study. Briefly, phase 2 of the Québec Family Study is composed of 858 subjects (374 men and 484 women). In order to have a population that is as representative as possible of the population in the Greater Québec City area, all subjects within the designated age-group for whom variables of interest were available were selected to enter the regression as controls. Subjects gave their written consent to participate in these studies, which received the approval of the Laval University Medical Ethics Committee.

It is important to note that, following the withdrawal of fenfluramine and dexfenfluramine from the market because of their potential associations with disturbances in cardiac valvular function (Khan et al. 1998; Weissman et al. 1998), all subjects (including those taking placebos) were subjected to an echocardiogram. Following this assessment, a detailed analysis of cardiac valvular function was performed by cardiologists, who detected no abnormalities in response to the use of fenfluramine under these conditions (Prud'homme et al. 1999). A variable period of time had elapsed between the end of the programme and this follow-up visit, with a range from 43 to 118 weeks.

\section{Anthropometric measurements}

Body weight was measured using a standard beam scale, $1 \mathrm{~h}$ after a standardized breakfast, while subjects were in their swimsuits (same at every measure). Residual lung volume was assessed by the closed-circuit He-dilution method before subjects' body density was measured (Meneely \& Kaltreider, 1949). Body density was determined by hydrodensitometry (Behnke \& Wilmore, 1974), and the Siri (1956) formula was used to estimate percentage body fat from body density, while FM and FFM were estimated from the derived percentage body fat and total body weight.

\section{Measurement of resting energy expenditure}

REE was measured by indirect calorimetry after a $12 \mathrm{~h}$ overnight fast; subjects were instructed to refrain from physical activity on the day before this measurement. After a 15 min resting period, expired gas was collected through a mouthpiece for $15 \mathrm{~min}$; the nose was clipped through the entire sampling period in obese subjects. In this group $\mathrm{O}_{2}$ and $\mathrm{CO}_{2}$ concentrations were determined by non-dispersive i.r. analysis (Uras $10 \mathrm{E}$; Hartmann \& Braun, Frankfurt, Germany), and pulmonary ventilation was determined using an S-430A measurement system (Ventura, CA, 
Table 1. Characteristics of male subjects participating in the study

(Mean values with their standard errors for fifteen obese men and 112 control men)

\begin{tabular}{|c|c|c|c|c|c|c|c|c|c|c|c|c|c|}
\hline & & & \multicolumn{8}{|c|}{ Obese men } & & & \\
\hline & \multicolumn{2}{|c|}{ Controls } & \multicolumn{2}{|c|}{ Baseline } & \multicolumn{2}{|c|}{ Week 2} & \multicolumn{2}{|c|}{ Week 8} & \multicolumn{2}{|c|}{ Week 17-19 } & \multicolumn{3}{|c|}{ Statistical significance of effect of: } \\
\hline & Mean & SE & Mean & SE & Mean & SE & Mean & SE & Mean & SE & Time & Treatment† & Treatment $\times$ time \\
\hline Body weight $(\mathrm{kg})$ & $86 \cdot 1$ & 1.9 & $104 \cdot 2^{\star \star}$ & $2 \cdot 6$ & $102 \cdot 7^{* *}$ & 2.5 & $96 \cdot 7$ & $2 \cdot 6$ & 93.8 & 2.4 & $P<0.05$ & NS & NS \\
\hline Fat mass $(\mathrm{kg})$ & $24 \cdot 1$ & $1 \cdot 2$ & $38 \cdot 9^{\star \star}$ & $1 \cdot 7$ & $37 \cdot 6^{\star \star}$ & $1 \cdot 3$ & $32 \cdot 9^{\star \star}$ & 1.5 & $29 \cdot 6$ & $1 \cdot 3$ & $P<0.05$ & NS & NS \\
\hline Fat-free mass $(\mathrm{kg})$ & $62 \cdot 0$ & 0.8 & $65 \cdot 3$ & 1.9 & $65 \cdot 2$ & $1 \cdot 6$ & $63 \cdot 8$ & 1.9 & $64 \cdot 2$ & $2 \cdot 0$ & NS & NS & NS \\
\hline BMI $\left(\mathrm{kg} / \mathrm{m}^{2}\right)$ & 28.5 & 0.6 & $34 \cdot 3^{\star *}$ & 0.6 & $33 \cdot 7^{\star \star}$ & 0.6 & $31 \cdot 7$ & 0.6 & $30 \cdot \overline{9}$ & 0.6 & $P<0.05$ & NS & NS \\
\hline
\end{tabular}

Mean values were significantly different from those for controls: ${ }^{\star *} P<0.013$.

$\dagger$ Either fenfluramine or placebo; for details of experimental procedures, see p. 716 .

USA). In control subjects tested in the context of the Québec Family Study indirect calorimetry measurements were performed using an open-circuit ventilated-hood system over a $30 \mathrm{~min}$ period. Gas analyses were assayed with an infrared $\mathrm{CO}_{2}$ analyser (Amatek S-3A; Thermox Instruments Division, Pittsburgh, PA, USA) and a $\mathrm{Zr}$ cell $\mathrm{O}_{2}$ analyser (Amatek CD-3A). Both systems were calibrated before each test, and the Weir (1949) formula was used to determine the energy equivalent of $\mathrm{O}_{2}$ volume.

\section{Calculation of predicted resting energy expenditure and of changes from baseline}

Step-wise multiple regression analyses were performed to identify predictors of REE within men and women who served as control subjects. The following independent variables were entered into the model: age; FM; FFM. The following equations were retained for men and women respectively:

$$
\begin{array}{lll}
\mathrm{REE}=1.28+0.023 \times \mathrm{FM} & (\mathrm{kg})+0.052 \times \mathrm{FFM} & (\mathrm{kg}) \\
\mathrm{REE}=0.85+0.016 \times \mathrm{FM} & (\mathrm{kg})+0.059 \times \mathrm{FFM} \quad(\mathrm{kg}) .
\end{array}
$$

These equations were used to predict REE at baseline, after 2 and 8 weeks as well as after the end of the programme in obese men and women. Changes in REE (extrapolated over $24 \mathrm{~h}$ ) from baseline for measured and predicted values of REE respectively were calculated as follows:

[(measured REE at weeks 2,8 and 17-19)

$$
\text { - measured REE (baseline)] } \times 1440 \text {; }
$$

[(predicted REE at weeks 2, 8 and 17-19)

$$
\text { - predicted REE (baseline)] } \times 1440] \text {. }
$$

Hence, adaptive thermogenesis was considered as the difference between the changes in predicted REE from the reference equations and the changes in measured REE.

\section{Statistical analysis}

The Jump Software 3.1.6.2 from the SAS Institute Inc. (Cary, NC, USA) was used for all analyses. Unpaired Student's tests with a Bonnferoni correction were performed to assess differences between control subjects and obese individuals at all four different measurement periods $(P \leq 0.013)$. Paired $t$ tests were performed to compare predicted and measured values of REE in lean (BMI $\left.<25 \mathrm{~kg} / \mathrm{m}^{2}\right)$, overweight $\left(25 \mathrm{~kg} / \mathrm{m}^{2} \leq\right.$ BMI $\left.<30 \mathrm{~kg} / \mathrm{m}^{2}\right)$ and obese (BMI $\geq 30 \mathrm{~kg} / \mathrm{m}^{2}$ ) subjects, to assess the applicability of this equation to subjects of varying degrees of adiposity within the control population. A one-way ANOVA for repeated measures was used to assess the effects of treatment (fenfluramine and placebo) and time, and their interaction on all dependent variables within each gender. Predicted values of REE were compared with measured values of REE by means of paired $t$ tests with a Bonnferoni correction at all sampling times in obese subjects $(P \leq 0.013)$. A two-way ANOVA for repeated measures (time) was performed to assess the effects of treatment and prediction (measured $v$. predicted) in the changes of REE from baseline within each gender. When this ANOVA revealed a significant time by prediction effect, post-hoc comparisons were performed by paired $t$ tests with a Bonnferoni correction $(P \leq 0.017)$. All data are expressed as mean with their standard errors.

\section{Results}

Characteristics of obese subjects who underwent the weight loss programme and of controls from the Québec Family Study are presented in Tables 1 and 2 for men and women respectively. Age and height were similar between control and obese subjects (results not shown). Body weight, FM and BMI were all significantly lower in the control subjects when compared with values measured at baseline and at 2 weeks in obese men $(P<0.013)$ and women $(P<0.05)$. These three variables were also significantly lower in controls than in obese women after 8 weeks and at the end of treatment $(P<0.05)$, whereas no difference was observed between control and obese men at these sampling times. FFM in obese subjects was not significantly different between control and obese subjects, and this variable remained comparable with that observed in controls throughout the weight-loss programme in both men and women. This programme significantly reduced body weight, FM and BMI in obese men and women. However, the programme did not significantly reduce FFM in obese men or women. A significant treatment $\times$ time interaction effect was observed for BMI in women $(P<0.05)$, 
Table 2. Characteristics of female subjects participating in the study

(Mean values with their standard errors for twenty obese women and 166 control women)

\begin{tabular}{|c|c|c|c|c|c|c|c|c|c|c|c|c|c|}
\hline & & & \multicolumn{8}{|c|}{ Obese women } & & & \\
\hline & \multicolumn{2}{|c|}{ Controls } & \multicolumn{2}{|c|}{ Baseline } & \multicolumn{2}{|c|}{ Week 2} & \multicolumn{2}{|c|}{ Week 8} & \multicolumn{2}{|c|}{ Week 17-19 } & \multicolumn{3}{|c|}{ Statistical significance of effect of: } \\
\hline & Mean & SE & Mean & SE & Mean & SE & Mean & SE & Mean & SE & Time & Treatment† & Treatment $\times$ time \\
\hline Body weight $(\mathrm{kg})$ & $70 \cdot 9$ & 1.5 & $93 \cdot 6^{*}$ & $2 \cdot 9$ & $92 \cdot 7^{*}$ & $2 \cdot 9$ & $88.5^{*}$ & $2 \cdot 8$ & $85 \cdot 5^{\star}$ & $2 \cdot 8$ & $P<0.05$ & NS & NS \\
\hline Fat mass $(\mathrm{kg})$ & 25.5 & $1 \cdot 1$ & $46 \cdot 4^{*}$ & $2 \cdot 1$ & $45 \cdot 8^{*}$ & $2 \cdot 0$ & $42 \cdot 6^{*}$ & $2 \cdot 0$ & $40 \cdot 5^{\star}$ & $2 \cdot 1$ & $P<0.05$ & NS & NS \\
\hline Fat-free mass $(\mathrm{kg})$ & 45.4 & 0.5 & $47 \cdot 2$ & $1 \cdot 2$ & 46.9 & 1.2 & $46 \cdot 0$ & $1 \cdot 1$ & $45 \cdot 0$ & 1.0 & NS & NS & NS \\
\hline BMI $\left(\mathrm{kg} / \mathrm{m}^{2}\right)$ & $27 \cdot 8$ & 0.6 & $36 \cdot 8^{*}$ & 0.9 & $36 \cdot 4^{*}$ & 0.9 & $34 \cdot 8^{*}$ & 0.9 & $33 \cdot 6^{*}$ & 1.0 & $P<0.05$ & NS & $P<0.05$ \\
\hline
\end{tabular}

Mean values were significantly different from those for controls: ${ }^{\star} P<0.05$

$\dagger$ Either fenfluramine or placebo; for details of experimental procedures, see p. 716

revealing a slightly greater decrease in this variable in women who received fenfluramine during this intervention.

Fig. 1 shows the regression plots derived from the control population in men (Fig. 1(a)) and in women (Fig. 1(b)). Step-wise multiple regression analyses were performed in men and women who served as controls to identify predictors of REE while considering age, FM and FFM as independent variables. In men FFM was the strongest predictor of REE $\left(r^{2} 0 \cdot 62, P<0.0001\right)$, but entering FM into the model slightly increased the predictability of the equation $\left(r^{2} 0 \cdot 67, P<0 \cdot 0001\right)$ (Fig. 1(a)). FFM was also the strongest predictor of REE in women $\left(r^{2} 0.63, P<\right.$ 0.0001), but adding FM into the model increased the predictability of the equation to $68 \%$ of the variance $(P<$ 0.0001; Fig. 1(b)). In order to assess whether the equations that were used to predict REE in obese subjects were equally applicable to subjects of varying degrees of adiposity, these equations were applied to lean (BMI $\left.<25 \mathrm{~kg} / \mathrm{m}^{2}\right)$, overweight $\left(25 \mathrm{~kg} / \mathrm{m}^{2} \leq \mathrm{BMI}<30 \mathrm{~kg} / \mathrm{m}^{2}\right)$ and obese (BMI $\geq 30 \mathrm{~kg} / \mathrm{m}^{2}$ ) subjects within the control population. As shown in Fig. 2, measured and predicted REE were not significantly different in lean, overweight or obese men or women, thus indicating that the prediction equations used were applicable to the whole sample, irrespective of differences in adiposity.

Table 3 presents values for measured REE and predicted REE at all sampling times during the study in obese subjects. Both measured and predicted REE were significantly $(P<0.05)$ reduced in men in response to this weight-loss intervention. Although measured values of REE were also slightly changed in response to the weightloss programme in women, these differences were not significant. As expected, predicted REE was significantly $(P<0.05)$ reduced in obese women as well. In obese men at baseline, measured REE was essentially the same as the predicted value. By week 8 , the predicted value was significantly greater than the measured value $(P<0 \cdot 01)$ and, although the predicted value of REE also tended to be greater than the measured REE after the end of the programme in men, this difference was not statistically significant. A different pattern was observed in women, since they started by having a significantly greater REE than the predicted value $(P<0 \cdot 01)$. However, after 2 and 8 weeks of energy restriction, measured values of REE were no longer different from those predicted. At weeks 17-19, after the programme, predicted values of REE in women were lower than those measured $(P=0.01)$. It should be noted that no effect of fenfluramine was observed on REE during weight loss in either men or women.

Fig. 3 shows the significant effects of time $(P<0.001)$ and of prediction (measured $v$. predicted changes of REE; $P<0.001)$ in men. In women an effect of prediction was also observed $(P<0.05)$ as well as a time $\times$ prediction interaction $(P=0.07)$ that revealed a significant difference between measured and predicted changes at weeks 2 and 8 $(P<0.01)$. However, no significant difference between measured and predicted changes in REE were observed by the end of the programme in this group.

Table 3. Predicted and measured resting energy expenditure $(\mathrm{kJ} / \mathrm{min})$ in obese men and women at all sampling times while undergoing a 15week weight-loss programme†

(Mean values with their standard errors for fifteen obese men and twenty obese women)

\begin{tabular}{|c|c|c|c|c|c|c|c|c|c|c|c|}
\hline & \multicolumn{2}{|c|}{ Baseline } & \multicolumn{2}{|c|}{ Week 2} & \multicolumn{2}{|c|}{ Week 8} & \multicolumn{2}{|c|}{ Weeks 17-19 } & \multicolumn{3}{|c|}{ Statistical significance of effect of: } \\
\hline & Mean & SE & Mean & SE & Mean & SE & Mean & SE & Time & Treatment\| & Treatment $\times$ time \\
\hline \multicolumn{12}{|l|}{ Men } \\
\hline Measured & $5 \cdot 80$ & 0.12 & 5.43 & 0.14 & 4.91 & 0.16 & 5.09 & 0.09 & $P<0.05$ & NS & NS \\
\hline Predicted $\ddagger$ & $5 \cdot 60$ & 0.11 & $5 \cdot 55$ & $0 \cdot 10$ & $5 \cdot 38^{\star \star}$ & 0.11 & $5 \cdot 32$ & 0.08 & $P<0.05$ & NS & NS \\
\hline \multicolumn{12}{|l|}{ Women } \\
\hline Measured & 4.94 & 0.12 & $4 \cdot 48$ & 0.11 & $4 \cdot 39$ & 0.12 & $4 \cdot 75$ & 0.21 & NS & NS & NS \\
\hline Predicted§ & $4 \cdot 38^{* *}$ & 0.09 & $4 \cdot 36$ & 0.09 & $4 \cdot 25$ & 0.09 & $4 \cdot 16^{\star *}$ & 0.08 & $P<0.05$ & NS & NS \\
\hline
\end{tabular}

Mean values were significantly different from measured values: ${ }^{\star \star} P<0.013$

† For details of subjects and experimental procedures, see Tables 1 and 2 and p. 716 .

$\ddagger$ Resting energy expenditure $=1.28+0.023 \times$ fat mass $(\mathrm{kg})+0.052 \times$ fat - free mass $(\mathrm{kg})$.

$\S$ Resting energy expenditure $=0.85+0.016 \times$ fat mass $(\mathrm{kg})+0.059 \times$ fat - free mass $(\mathrm{kg})$

II Either fenfluramine or placebo; for details, see p. 716 . 
(a)

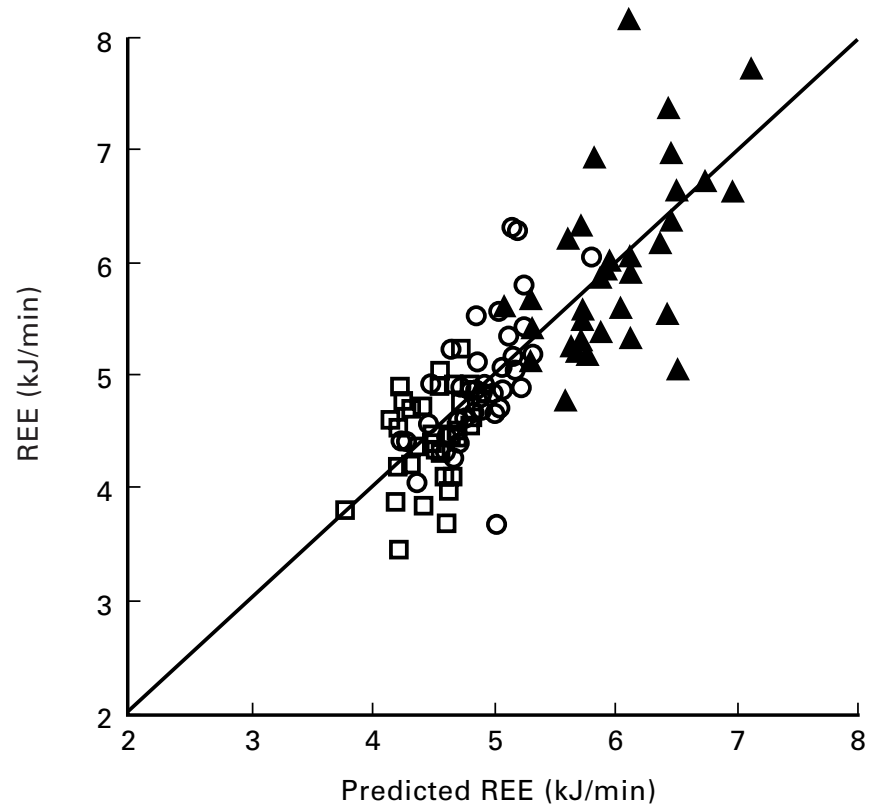

(b)

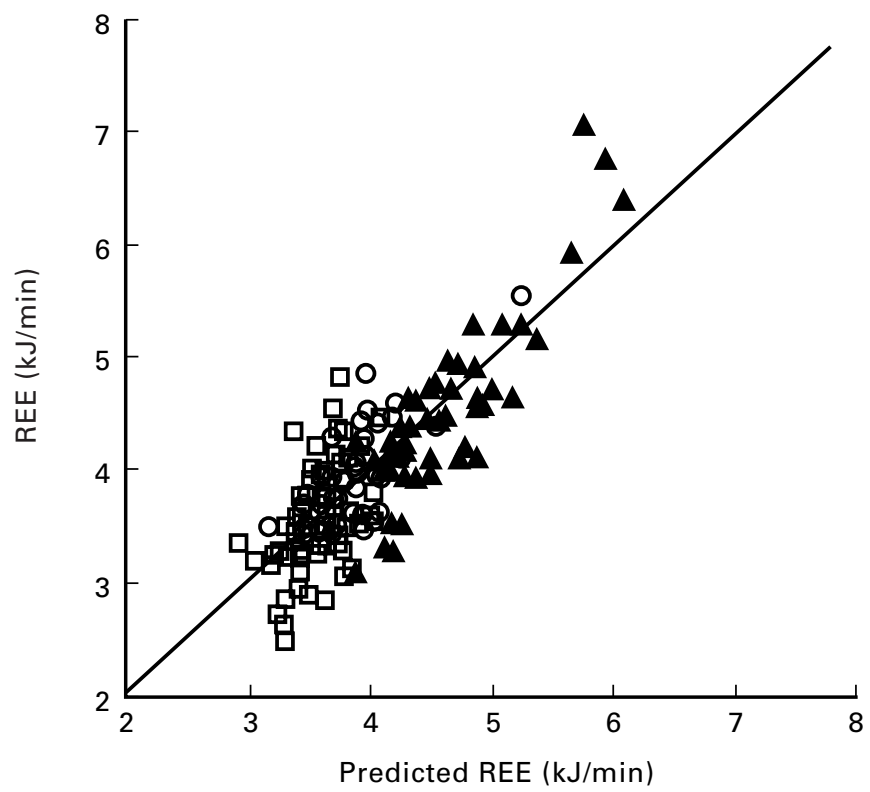

Fig. 1. Reference regressions for male (a) and female (b) control subjects. ( $\square$ ), Lean (BMI $\left.<25 \mathrm{~kg} / \mathrm{m}^{2}\right)$; (O), overweight $\left(25 \mathrm{~kg} / \mathrm{m}^{2} \leq \mathrm{BMl}<30 \mathrm{~kg} / \mathrm{m}^{2}\right)$; $(\Lambda)$, obese $\left(B M I \geq 30 \mathrm{~kg} / \mathrm{m}^{2}\right)$. For men, resting energy expenditure (REE; $\mathrm{kJ} /$ $\min )=1.28+0.023$ fat mass $(\mathrm{FM} ; \mathrm{kg})+0.052$ fat-free mass $(\mathrm{FFM} ; \mathrm{kg}) ; r^{2}$ $0.67, P<0.0001$. For women, REE $=0.85+0.016$ FM + 0.059 FFM; $r^{2}$ $0.68, P<0.0001$. For details of subjects and procedures, see Tables 1 and 2 and p. 716 .

Table 4 presents results from a step-wise multiple regression aimed at identifying the best predictors of deviations from the predicted REE. No significant predictor of deviations was found at 2 weeks. However, the initial REE predicted $20 \%(P=0.008)$ of the variance in deviations from the predicted REE after 8 weeks of energy restriction. Adding baseline values of FFM and gender into the model increased the predictability to $48 \%(P=$ $0.0002)$ and $59 \%(P=0.006)$ of the variance in REE after 8 weeks of energy restriction respectively. More detailed analyses of these results revealed that individuals with high REE, and low FFM, at the beginning of the weight-loss programme were at greater risk of falling below their predicted REE, particularly for women. In addition, deviations from the predicted values at the end of the energy restriction were also significantly predicted by initial levels of REE (11\%,P=0.05). Again, individuals with higher REE at the beginning of the weight-loss programme seemed to be more likely to fall below their predicted REE at the end of the weight-loss programme. 

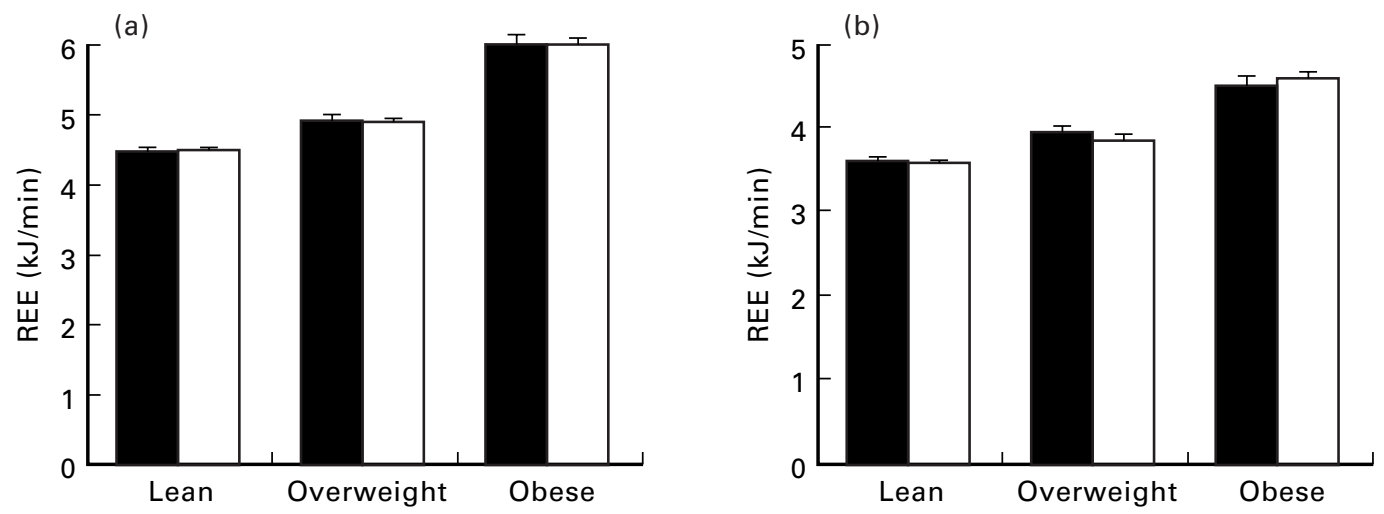

Fig. 2. Predicted ( $\square$ ) and measured ( $\square$ ) resting energy expenditure (REE) for male (a) and female (b) lean (BMI $\left.<25 \mathrm{~kg} / \mathrm{m}^{2}\right)$, overweight $(25 \mathrm{~kg} /$ $\left.\mathrm{m}^{2} \leq \mathrm{BMI}<30 \mathrm{~kg} / \mathrm{m}^{2}\right)$ and obese $\left(\mathrm{BMI} \geq 30 \mathrm{~kg} / \mathrm{m}^{2}\right.$ ) control subjects. For details of subjects and experimental procedures, see Tables 1 and 2 and p. 716. Values are means with their standard errors represented by vertical bars.

\section{Discussion}

To our knowledge, the present study is the first to produce sequential objective quantitative information on the adaptive component of thermogenesis which appears when human subjects are exposed to prolonged energy restrictions aimed at inducing weight loss. Moreover, the present study also demonstrated quite clearly that once energy balance was recovered, even in a reduced obese state, this adaptive thermogenesis was attenuated. Finally, these results suggest that individuals, particularly women, with higher REE and lower FFM at the beginning of a weight-loss programme are more likely to fall below their predicted REE.

One major concern regarding these results is the fact that the reference equations used to predict REE in obese individuals might not be universally applicable to individuals of varying degrees of adiposity within the control population. In order to assess whether the equations used in the present study were indeed equally applicable to subjects of varying adiposity, control subjects were subdivided into lean (BMI $\left.<25 \mathrm{~kg} / \mathrm{m}^{2}\right)$, overweight $\left(25 \mathrm{~kg} / \mathrm{m}^{2} \leq \mathrm{BMI}\right.$ $<30 \mathrm{~kg} / \mathrm{m}^{2}$ ) and obese $\left(\right.$ BMI $\left.\geq 30 \mathrm{~kg} / \mathrm{m}^{2}\right)$. The global equation was then applied to each subgroup and the predicted and measured REE were then compared within each of these subgroups. The results of these analyses revealed that for both men and women the equations used were equally applicable to individuals of varying adiposity within the control population. For this reason, we are inclined to think that the reference equations used in the present study do not constitute a factor that would invalidate the results.

Interestingly, when we compared REE with measured REE in obese men at baseline, no differences were observed between these variables. These results are consistent with the notion that obesity favours the reestablishment of energy and fat balance (Schutz et al. 1992; Astrup et al. 1994). Although subjects were instructed to maintain their habitual dietary habits before the beginning of the programme, we cannot exclude the possibility that women might have relaxed their dietary control before undertaking a prolonged energy deprivation. Since overfeeding increases REE (Tremblay et al. 1992), this factor could possibly explain why greater than predicted levels of REE were observed in our obese women, but this phenomenon will need further investigation.

When changes in REE are extrapolated over a $24 \mathrm{~h}$ period, the observed changes in FFM and FM observed
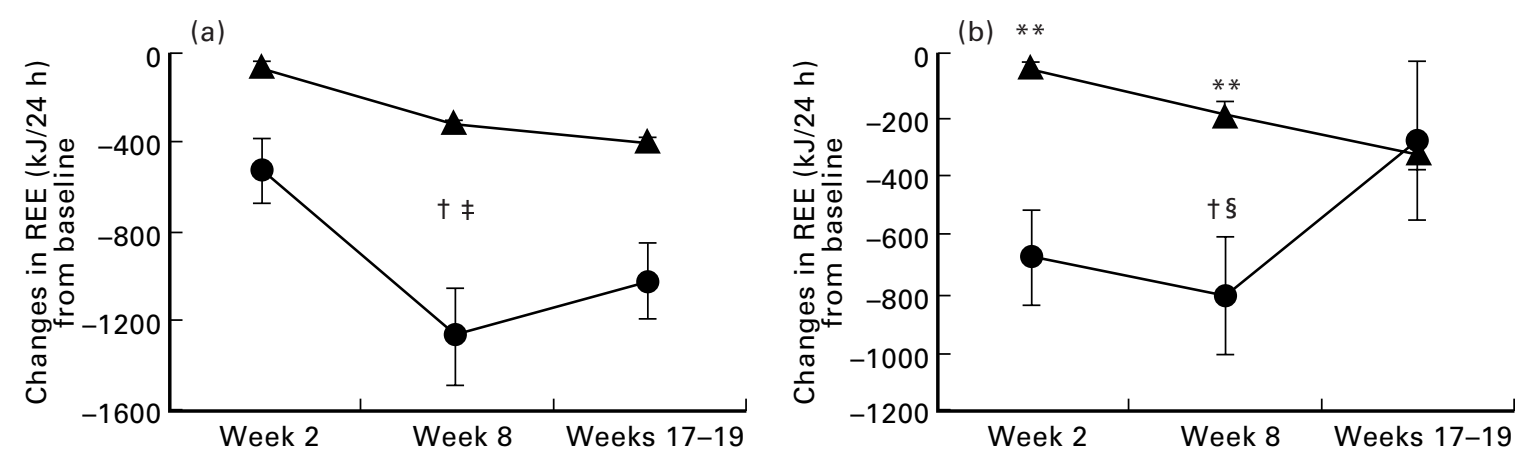

Fig. 3. Predicted $(\boldsymbol{\Lambda})$ and measured $(\bullet)$ changes in resting energy expenditure (REE) from baseline extrapolated over $24 \mathrm{~h}$ in obese men (a) and women (b) undergoing a 15-week weight-loss programme. For details of subjects and experimental procedures, see Tables 1 and 2 and p. 716. Values are means with their standard errors represented by vertical bars. Mean values were significantly different from those for measured REE: ${ }^{\star \star} P<0.01$. †The effect of time was significant: $(P<0.001)$. $¥$ The effect of prediction (predicted $v$. measured) was significant $(P<0.05)$. $\S$ The effect of time $\times$ prediction $(P=0.07)$. 
Table 4. Step-wise multiple regression analysis examining predictors of deviations in resting energy expenditure (REE) at 2 and 8 weeks, and after the end of the weight-loss programme (weeks 17-19)

\begin{tabular}{lcccc}
\hline Dependent variable & Step no. & Predicting variable & $r^{2}$ & Statistical significance: $P$ \\
\hline Deviations at week 8 & 1 & Initial REE & 0.20 & 0.008 \\
& 2 & Initial FFM & 0.48 & 0.0002 \\
Deviations at weeks 17-19 & 3 & Gender & 0.59 & 0.006 \\
\hline
\end{tabular}

Probability to enter the model, $P \leq 0.05$. Dependent variables were deviations at 2 and 8 weeks and at the end of the programme; predicting variables were gender, age, initial fat mass, (FM) and fat-free mass (FFM), initial REE and RQ, and changes in FM and FFM at respective times.

after 2 weeks in men should have caused a $57 \mathrm{~kJ} / \mathrm{d}$ decrease in REE, based on the reference regression, whereas the actual decrease was $526 \mathrm{~kJ} / \mathrm{d}$. A similar observation was seen in women for whom a $36 \mathrm{~kJ} / \mathrm{d}$ fall in REE was expected from the observed changes in the lean and fat compartments, whereas a $671 \mathrm{~kJ} / \mathrm{d}$ decrease in REE was measured. This was also the case after 8 weeks, as changes in measured REE values remained below the predicted scores in men $(-1265 v .-312 \mathrm{~kJ} / \mathrm{d})$ and women $(-804 \mathrm{~kJ} / \mathrm{d} v .-190 \mathrm{~kJ} / \mathrm{d})$. However, at the end of the programme, when subjects were no longer energy restricted, as reflected by their stable body weight, predicted and measured changes of REE were no longer different in women, whereas in men, although these values were closer together than at week 8 , measured changes still remained below predicted changes in REE. Our results are in accordance with those of Leibel et al. (1995), who demonstrated a greater than predicted decrease in daily energy expenditure of the same magnitude in obese subjects $(-573 \mathrm{~kJ} / \mathrm{d})$ in response to a $10 \%$ decrease in body weight. Indeed, this observation is quite similar to our report in men after a comparable $10 \%$ weight loss $(-622 \mathrm{~kJ} / \mathrm{d})$. We did not observe such a difference in women, even if they had lost a comparable relative amount of body weight to that of men (9\% initial body weight $v$. $10 \%$ initial body weight), since once the women had reached weight stability in the reduced obese state, differences between the changes in predicted and measured values of REE were no longer observed. One important difference between the studies is the fact that multiple measures of REE were performed throughout the weightloss programme in the present study. This strategy established that REE falls more than predicted early into a weight-loss programme, before any marked changes in body weight and composition have occurred, and remains below predicted changes until energy balance has been recovered in a reduced obese state. Our findings are also in agreement with a recent study in which it was shown that subjects from the Biosphere 2 experiment had a lower than predicted total energy expenditure after a prolonged negative energy balance. However, this difference in energy expenditure seemed to be mostly explained by decreased spontaneous physical activity (Weyer et al. 2000).

Results from the present study show that the deviations from the predicted values were reduced once weight stability, and possibly energy balance, was recovered after the end of the dynamic weight-loss phase in men, but more strikingly in women. Hence, the most marked deviation in REE from predicted values seems to be observed when individuals are energy deprived. This finding is, in our opinion, important, because it might explain why in some cases individuals fail to respond to an energy-restricted diet as would be expected. Indeed, it should be noted that the data that are presented are mean values and that, for some individuals, differences between predicted and measured values of REE were as much as $1200-1600 \mathrm{~kJ} / \mathrm{d}$ as early as 2 weeks after the beginning of the energy restriction. Under such circumstances, it would be highly relevant to identify these individuals in order to develop adequate treatment strategies for those who are certainly more prone not to respond to an energy-restricted diet. In this sense, our analyses revealed that individuals who presented higher REE and lower FFM at the beginning of the weight-loss programme were more at risk of falling below their predicted REE during an energy-restricted diet aimed at inducing weight loss, particularly for women.

As thermogenesis in man is largely a function of sympathetic nervous system activity (Saris, 1995) and as sympathetic nervous system activity has been shown to decrease in response to weight loss (Arone et al. 1995), it could be suggested that the disproportionate decrease in REE observed in response to weight loss in the present study was a reflection of a decreased sympathetic tone. This is in agreement with recent results that have shown that a change in $24 \mathrm{~h}$ urinary noradrenaline excretion is an independent predictor of changes in REE in response to weight changes (Rosenbaum et al. 2000). This notion fits with the observation that the most striking decline in leptin levels in response to energy restriction is seen before any major changes in body fatness occur (Geldszus et al. 1996; Wadden et al. 1998; Wisse et al. 1999), more particularly in the context where leptin has been shown to be associated with sympathetic nervous system activity in human subjects (Snitker et al. 1997). Moreover, we recently reported that changes in REE and fat oxidation resulting from weight loss were more closely related to changes in leptin levels than to changes in body weight or composition, particularly in men (Doucet et al. 2000). Hence, the facultative component of REE during weight loss could be explained by hormonal fluctuations, as is the case for leptin, which could attenuate sympathetic nervous system activity and possibly protect energy stores by reducing REE below the predicted level in some individuals. If leptin levels are sensitive to the energy flux (Levine \& Billington, 1998), it could explain why, at the end of the present weight-loss programme, when subjects were again given free access to foods, predicted and measured REE became more similar than during the active weight-loss phase. Another possible explanation for this phenomenon was 
provided in a recent re-analysis of the results from the Minnesota experiment (Keys et al. 1950). In this model, it was proposed that reductions in body fat during prolonged underfeeding might trigger the appearance of adaptive thermogenesis (change in BMR adjusted for changes in body composition) in order to favour the restoration of body fat reserves via an autoregulatory feedback system (Dulloo et al. 1997).

It has been previously reported that dexfenfluramine acutely increased resting metabolic rate and dietaryinduced thermogenesis in obese males (Scalfi et al. 1993). Moreover, this compound has been shown to prevent the fall in resting metabolic rate, when it was expressed on per kg body weight basis, during weight loss in premenopausal obese women (Van Gaal et al. 1995). However, other researchers have failed to reproduce these observations (Lafreniere et al. 1993; Recasens et al. 1995). Available data on fenfluramine suggest that, although it might affect postprandial energy expenditure, no effect was observed on REE in either animals (Stallone \& Levitsky, 1994) or human subjects (Wales, 1980). As for previous results, our analyses did not reveal any significant effects of fenfluramine on either the changes of REE during weight loss or on the deviations from predicted REE. However, we cannot come to a conclusion with certainty on this issue, since the number of placebo-treated individuals was not sufficient to test this hypothesis.

In summary, these results emphasize the existence of an adaptive component of thermogenesis during weight loss in both men and women, and produced quantitative information on this phenomenon. Moreover, this adaptive thermogenesis seems to be mainly attributable to the energy restriction, since it appeared early in the weight-loss programme, before any major changes in body weight or composition were observed. This finding is reinforced by the observation that once body weight stability and possibly energy balance had been recovered at the end of the programme, adaptive thermogenesis was attenuated, particularly in women where it completely disappeared.

\section{Acknowledgements}

This research was funded by Servier Canada and the Medical Research Council of Canada.

\section{References}

Arone LJ, Mackintosh R, Rosenbaum M, Leibel RL \& Hirsch J (1995) Autonomic nervous system activity in weight gain and weight loss. American Journal of Physiology 269, R222-R225.

Association Diabète Québec (1993) Plan d'alimentation avec le système d'échanges (Food exchange system). Montréal, Canada: Groupe Litho Graphique.

Astrup A, Buemann B, Western P, Toubro S, Raben A \& Christensen NJ (1994) Obesity as an adaptation to a high-fat diet: evidence from a cross-sectional study. American Journal of Clinical Nutrition 59, 350-355.

Behnke AR \& Wilmore JT (1974) Evaluation and Regulation of Body Build and Composition, pp. 20-37. Englewood Cliffs, NJ: Prentice-Hall.

Dionne I, Després J-P, Bouchard C \& Tremblay A (1999) Gender difference in the effect of body composition on energy metabolism. International Journal of Obesity 23, 312-319.

Doucet E, St Pierre S, Almeras N, Mauriege P, Richard D \& Tremblay A (2000) Changes in energy expenditure and substrate oxidation resulting from weight loss in obese men and women: is there an important contribution of leptin? Journal of Clinical Endocrinology and Metabolism 85, 15501556.

Dulloo AG, Jacquet J \& Girardier L (1997) Poststarvation hyperphagia and body fat overshooting in humans: a role for feedback signals from lean and fat tissues. American Journal of Clinical Nutrition 65, 717-723.

Ferraro R, Lillioja S, Fontvieille A-M, Rising R, Bogardus C \& Ravussin E (1992) Lower sedentary metabolic rate in women compared with men. Journal of Clinical Investigation 90, 780784.

Geldszus R, Mayr B, Horn R, Geisthovel F, von zur Muhlen A \& Brabant G (1996) Serum leptin and weight reduction in female obesity. European Journal of Endocrinology 135, 659-662.

Keys A, Brozek J, Henschel A, Mickelsen O \& Taylor HL (1950) The biology of human starvation. Minneapolis: University of Minneapolis Press.

Khan MA, Herzog CA, St Peter JV, Hartley GG, Madlon-Kay R, Dick CD, Asinger RW \& Vessey JT (1998) The prevalence of cardiac valvular insufficiency assessed by transthoracic echocardiography in obese patients treated with appetite-suppressant drugs. New England Journal of Medicine 10, 713-718.

Lafreniere F, Lambert J, Rasio E \& Serri O (1993) Effects of dexfenfluramine treatment on body weight and postprandial thermogenesis in obese subjects. A double-blind placebocontrolled study. International Journal of Obesity 17, 25-30.

Leibel RL \& Hirsch J (1984) Diminished energy requirements in reduced-obese patients. Metabolism 33, 164-169.

Leibel RL, Rosenbaum M \& Hirsch J (1995) Changes in energy expenditure resulting from altered body weight. New England Journal of Medicine 332, 621-628.

Levine AS \& Billington CJ (1998) Do circulating leptin concentrations reflect body adiposity or energy flux? American Journal of Clinical Nutrition 68, 761-762.

Meneely EA \& Kaltreider NL (1949) Volume of the lung determined by helium dilution. Journal of Clinical Investigation 28, 129-139.

Pasman WJ, Saris WH \& Westerterp-Plantenga MS (1999) Predictors of weight maintenance. Obesity Research 7, 43-50.

Prentice AM, Goldberg GR, Jebb SA, Black AE, Murgatroyd PR \& Diaz EO (1991) Physiological responses to slimming. Proceedings of the Nutrition Society 50, 441-458.

Prud'homme D, Langlais M, Samson MP, Gallagher P, Turcotte J, Tremblay A \& Després J-P (1999) Lack of major cardiac valvular abnormalities in asymptomatic obese men and women following a 3-month fenfluramine or dexfenfluramine treatment. International Journal of Obesity 23, S175.

Ravussin E, Lillioja S, Anderson TE, Christin L \& Bogardus C (1986) Determinants of 24-hour energy expenditure in man. Journal of Clinical Investigation 78, 1568-1578.

Ravussin E, Lillioja S, Knowler WC, Christin L, Freymond D, Abbott WGH, Boyce V, Howard BV \& Bogardus C (1988) Reduced rate of energy expenditure as a risk factor for bodyweight gain. New England Journal of Medicine 318, 467-472.

Recasens MA, Barenys M, Sola R, Blanch S, Masana L \& SalasSalvado J (1995) Effect of dexfenfluramine on energy expenditure in obese patients on a very-low-calorie diet. International Journal of Obesity 19, 162-168.

Rosenbaum M, Hirsch J, Murphy E \& Leibel RL (2000) Effects of changes in body weight on carbohydrate metabolism, catecholamine excretion, and thyroid function. American Journal of Clinical Nutrition 71, 1421-1432. 
Saris WH (1995) Effects of energy restriction and exercise on the sympathetic nervous system. International Journal of Obesity 19, Suppl. 7, S17-S23.

Scalfi L, D'Arrigo E, Carandente V, Coltorti A \& Contaldo F (1993) The acute effect of dexfenfluramine on resting metabolic rate and postprandial thermogenesis in obese subjects: a double-blind placebo-controlled study. International Journal of Obesity 17, 91-96.

Schutz Y, Tremblay A, Weinsier RL \& Nelson KM (1992) Role of fat oxidation in the long-term stabilization of body weight in obese women. American Journal of Clinical Nutrition 55, 670674.

Siri WE (1956) The gross composition of the body. Advances in Biology of Medicine and Physiology 4, 239-280.

Snitker S, Pratley RE, Nicolson M, Tataranni PA \& Ravussin E (1997) Relationship between muscle sympathetic nervous activity and plasma leptin concentration. Obesity Research $\mathbf{5}$, 338-340.

Stallone DD \& Levitsky DA (1994) Chronic fenfluramine treatment: effects on body weight, food intake and energy expenditure. International Journal of Obesity 18, 679-685.

Tremblay A, Despres JP, Theriault G, Fournier G \& Bouchard C (1992) Overfeeding and energy expenditure in humans. American Journal of Clinical Nutrition 56, 857-862.

Van Gaal LF, Vansant GA, Steijaert MC \& De Leeuw IH (1995) Effects of dexfenfluramine on resting metabolic rate and thermogenesis in premenopausal obese women during therapeutic weight reduction. Metabolism 44, 42-45.

van Gemert WG, Westerterp KR, Greve JW \& Soeters PB (1998) Reduction of sleeping metabolic rate after vertical banded gastroplasty. International Journal of Obesity 22, 343-348.

Wadden TA, Considine RV, Foster GD, Anderson DA, Sarwer DB
\& Caro JS (1998) Short- and long-term changes in serum leptin dieting obese women: effects of caloric restriction and weight loss. Journal of Clinical Endocrinology and Metabolism 83, 214-218.

Wadden TA, Foster GD, Stunkard AJ \& Conill AM (1996) Effects of weight cycling on the resting energy expenditure and body composition of obese women. International Journal of Eating Disorders 19, 5-12.

Wales JK (1980) The effect of fenfluramine on weight loss during restricted dietary regimes. International Journal of Obesity 4, $127-132$

Weir JB (1949) New methods for calculating metabolic rate with special reference to protein metabolism. Journal of Physiology 109, 1-9.

Weissman NJ, Tighe JFJ, Gottdiener JS \& Gwynne JT (1998) An assessment of heart-valve abnormalities in obese patients taking dexfenfluramine, sustained-release dexfenfluramine, or placebo. Sustained-Release Dexfenfluramine Study Group. New England Journal of Medicine 10, 725-732.

Westerterp KR, Meijer GA, Schoffelen P \& Janssen EM (1994) Body mass, body composition and sleeping metabolic rate before, during and after endurance training. European Journal of Applied Physiology 69, 203-208.

Weyer C, Walford RL, Harper IT, Milner M, MacCallum T, Tataranni PA \& Ravussin E (2000) Energy metabolism after 2 y of energy restriction: the biosphere 2 experiment. American Journal of Clincal Nutrition 72, 946-953.

Wisse BE, Campfield LA, Marliss EB, Morais JA, Tenenbaum R \& Gougeon R (1999) Effect of prolonged moderate and severe energy restriction and refeeding on plasma leptin concentrations in obese women. American Journal of Clinical Nutrition 70, $321-330$ 